\title{
SPONTANEOUS SEPARATION OF A GANGRENOUS LEG
}

\author{
J. L. C. Dall and A. McDougall, Glasgow, Scotland
}

A seventy-two-year-old woman was admitted to the Geriatric Assessment Unit in May 1967 with congestive heart failure. On admission she was cyanosed, with jugular venous engorgement, hepatomegaly and marked oedema of the legs. She was not hypertensive and there was no history of rheumatic or coronary heart disease; the cardiac failure had been precipitated by a chest infection. The heart was in sinus rhythm. After intensive therapy with oxygen, antibiotics, diuretics and digoxin she gradually improved.

At the time of her admission it had been noted that there was a blistered area on the left foot which was ascribed to a burn from a hot water bottle while she was still at home. As the swelling of the legs regressed it was seen that the area involved had turned black, and there was deep cyanosis of the toes. Further investigation revealed that the left femoral pulse

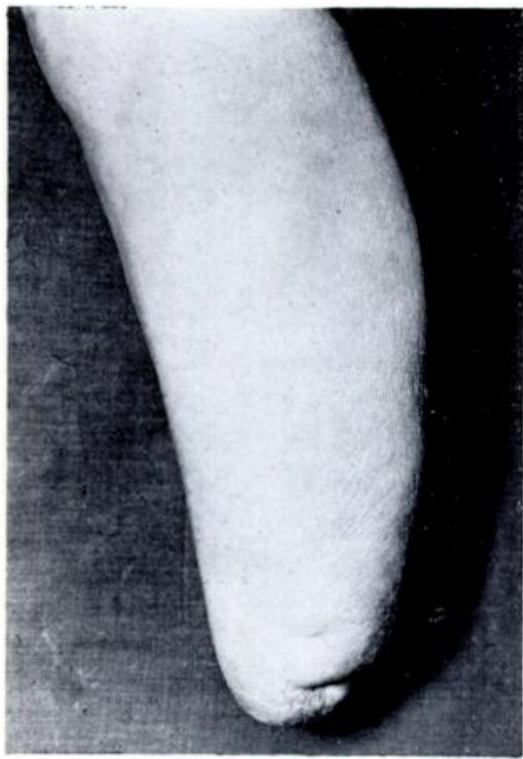

Fig. 1

The healed stump. was much weaker than the right, and no pulse could be palpated in the popliteal fossa or at the ankle.

Two weeks after her admission an area of gangrene had extended to involve the whole foot and it was decided that amputation would be necessary as soon as her general condition would permit. But she refused to consider amputation on the grounds that "if the Lord wanted to take her leg away, He would do it in His own good time". Fortunately the gangrene remained dry. Eighty days after her admission the leg separated spontaneously, leaving a clean granulated area in which the end of the tibia could just be seen. It was with reluctance that she allowed the gangrenous leg to be removed from her bed, and she would not permit any dressing to be applied to the stump in case it prevented the growth of a new limb, which she confidently expected. In spite of this the stump healed well (Fig. 1).

Four months after admission the stump was soundly healed and we tried to persuade her to accept an artificial limb. This she steadfastly refused for six months, but by the end of that time she had at last accepted the fact that another leg would not grow in place of the lost one as she had confidently expected. We fitted her with a patellar-tendon-bearing prosthesis and with this she walked immediately, using a walking frame and without any other assistance.

\section{DISCUSSION}

Spontaneous separation of a toe or finger occurs not infrequently in localised gangrene of the digits and it is an accepted procedure to wait for a line of demarcation and subsequent separation of a gangrenous toe. Spontaneous amputation of a limb, however, is rare: since 1900 only one such case has been recorded in the English literature (Svane 1965).

The immediate cause of the vascular occlusion in this case was not clear. As the pulse was regular and she had had neither a coronary incident nor endocarditis to give rise to embolism 
it is our belief that tissue anoxia caused by the oedema in the leg and aggravated by the severe cyanosis due to the chest infection and cardiac failure had finally reached a critical level in a limb where there was already established atheromatous vascular degeneration. This also probably explains the separation at mid-calf level and necrosis of the other tissues at suitable levels to allow excellent healing of a well-shaped stump which is completely free from pain and phantom limb phenomena.

Had she agreed to amputation originally, we would not have dared to consider a belowknee amputation having regard to her age and general state; we had in mind an above-knee or at best a through-knee amputation.

In the case of spontaneous separation recorded by Svane it took fifteen and a half months for the limb to separate, and the condition of the stump was such that a Gritti-Stokes amputation was subsequently carried out to obtain a satisfactory stump for limb fitting. In the case reported here we were fascinated not only with the spontaneous separation of the leg but by the natural capacity for healing at the line of demarcation, so that a well formed stump was left which could be fitted with a limb and which has given the patient no pain or trouble at any time. Although infection of the devitalised leg was probably prevented by the antibiotics given for her bronchitis, we can claim no credit for this excellently functioning below-knee amputation, and can only admire the way nature carried out this operation without our aid. Perhaps there is a lesson to be learned.

\section{REFERENCE}

Svane, S. (1965): Spontaneous Amputation of Gangrenous Leg. Journal of Bone and Joint Surgery, 47-A, 1401. 